\title{
ROCK FOLDS DUE TO WEATHERING
}

MARIUS R. CAMPBELL

The recent article by Professor Sardeson on "The Folding of Subjacent Strata by Glacial Action" is of considerable interest, and doubtless he has a case in which he can demonstrate the origin of the movement; but in studies of this kind it should be borne in mind that folds of a similar character occur far beyond the limit of glaciation, and that before attributing surface folds in general to glacial action other possible causes should be considered.

During a recent visit to the Carboniferous coal-field of Arkansas the writer had a good opportunity to examine a number of minor surface folds, which are very common in the great synclinal valleys adjacent to the Arkansas River. In most cases the folds were simply apparent in the disturbed sandy shales or thin-bedded sandstones in the roadway, and it was impossible to determine, without considerable excavation, the depth and extent of the disturbance.

In one case, however, an excellent example was obtained, which is illustrated in the accompanying cut. The occurrence is in the north part of Section 2, T. 7, N., R. 25 W., in the central northern portion of Logan County and about 50 miles east of Fort Smith.

The locality in which the fold is exposed is a shallow quarry in which sandstone for the construction of the large Catholic college near Spielersville was obtained. The surface material, as shown by the figure, consists of sandstone, the beds of which range in thickness from $\mathrm{I}$ to 5 or 6 inches. Near the bottom of the section shown in the cut is a rather heavy bed with a thickness of a foot or 18 inches. This is the main rock which is quarried, the surface material simply being stripped off for this purpose.

As shown in the photograph, the lower beds, especially the thick layer just mentioned and all below it, pass under the fold without being disturbed, the rocks having a dip of about $3^{\circ}$ to the southwest. Not only does the heavy bed shown at the bottom of the

I Journal of Geology, Vol. XIV, No. 3, pp. 226-32. 
photograph pass below the fold, but the overlying bed, having a thickness of about 4 inches, appears to be undisturbed also. Above this the strata, for a depth of from 3 to 4 feet, have been thrown into a distinct anticline with a height on its axis of at least 2 feet.

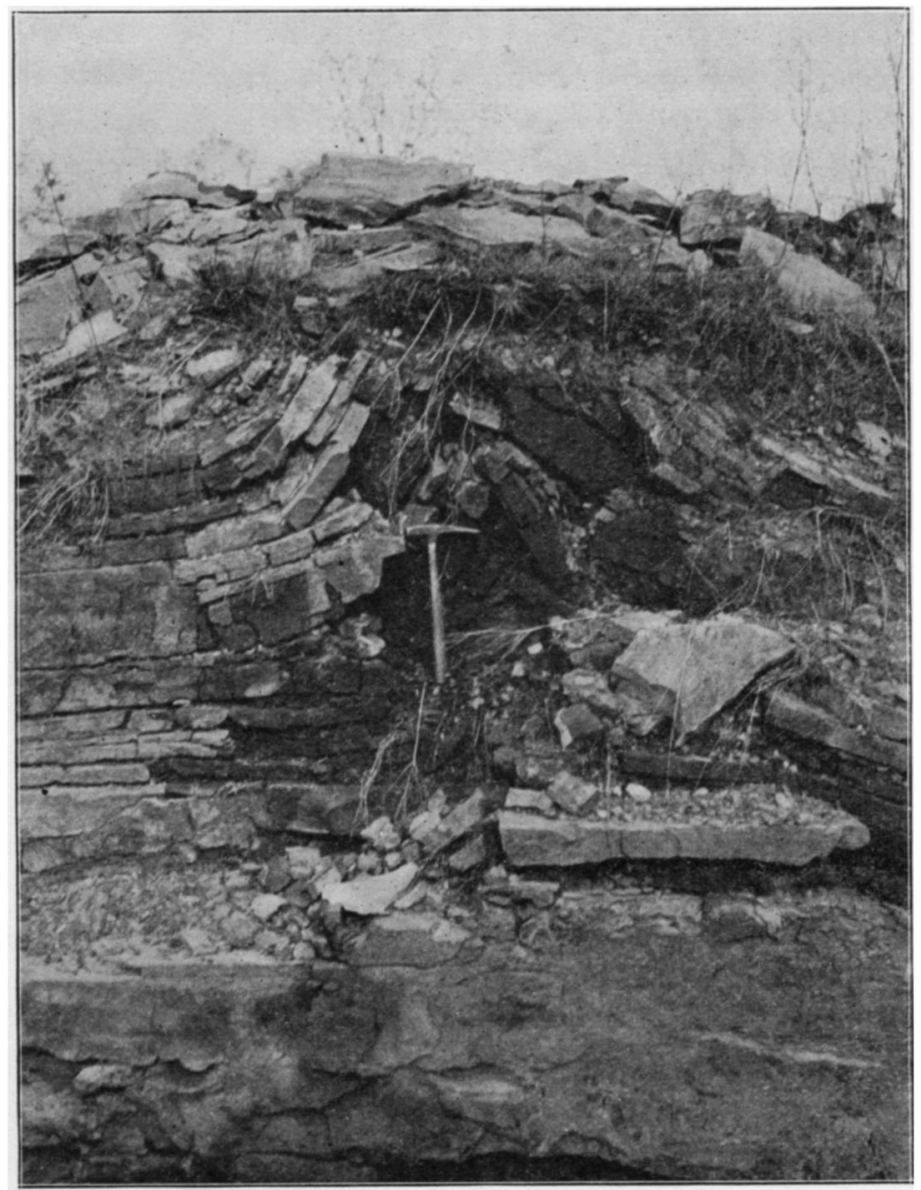

FIg. r.-Surface fold in thin-bedded sandstone near Spielersville, Ark.

The linear extent of this small fold is unknown, as the country immediately adjacent is covered by a heavy mantle of turf which makes it difficult to trace such features.

It is evident that glacial action has had no part in the formation 
of this fold, since it lies entirely beyond the southern limit of any known ice-sheet. The movement, however, is just as pronounced as in the cases shown by Professor Sardeson, and it is evident that some competent force other than moving ice has acted in a direction parallel with the bedding in producing the disturbance.

Since the underlying beds are not affected, it seems evident to the writer that the movement is not due to stresses which affect the crust of the earth to any great depth, for if such stresses are present, the heavy layer shown at the bottom of the photograph and the underlying beds would take the force of the strain, and the upper surface beds would be relieved. Moreover, the folds, so far as they have been observed, are surface features, and in this particular case occur near the outcrop of the beds affected. This entirely precludes the possibility of the movement being deep-seated, for in that event the rocks lying on the hillside above the fold, and between it and the point of outcrop, would probably have been moved bodily and no fold would have been produced.

Professor Sardeson has shown that similar features have been produced in Minnesota by the heaving action of frost, but in Arkansas the climate is so mild that freezing could not have played an important part in the formation of a fold. Moreover, the fold is not the result of vertical movement such as described by Professor Sardeson, but movement along the bedding planes of the rock.

The only way in which freezing could have produced such a result as the fold in question is by the cumulative effect of water freezing in the joints of the rock. This would tend to produce stresses in the surface rocks alone, and these stresses would continue or accumulate until they were relieved by some break or fold in the surface beds. Thus freezing might account for the phenomenon. If freezing alone were the active force, we should, however, find the results of its action much more common in northern regions than in southern; but, so far as the writer is aware, this is not the case. Therefore we must conclude that freezing, while possibly a factor in the case, has not been the dominant one.

The creep of surface rocks down the slope may be appealed to as a possible cause. It is true that in this region there is a close correspondence between the attitude of the beds and surface topog- 
raphy. Lightly dipping sandstones are usually marked by sloping surfaces, and, in this particular case, the ridge has an altitude of 60 or 80 feet above the surrounding plain. It hardly seems possible that in surface beds having a thickness of about 3 feet the superincumbent load of material which lies on the hill-slope above the point where the fold was formed has been sufficient to overcome friction and cause the rock to creep down the slope.

The only other explanation that seems at all plausible is that of expansion due to weathering. The process ordinarily called weathering is doubtless complex, consisting of chemical and mechanical changes in the body of the rock itself, most of which result in increased volume, but probably the most important element is the opening of joints and cleavage fissures. In this field jointing is highly developed. In unweathered sections the joints are scarcely visible, showing simply as incipient cracks in the rocks, but when exposed at the surface the joints are very abundant and almost always open.

The opening of joints is probably largely due to changes in temperature which result in the expansion and contraction of the rock itself, as well as of any rock particles which may have fallen into the cracks; to the freezing of water in the joints, and to the expansive force of roots. Although the amount of opening on each joint is small, the aggregate of hundreds or thousands of joints would tend to set up stresses parallel to the bedding, and in course of time these stresses would reach the point of rupture of the beds involved, and a fault or fold would be produced.

The phenomenon is most interesting to the students of structural geology, and it affords a measure of the amount of expansion these beds have undergone since the present surface was formed. 